\title{
ANALISIS PEMOTONGAN PPH PASAL 4 AYAT 2 TERHADAP LELANG PADA KANTOR PELAYANAN KEKAYAAN NEGARA DAN LELANG MANADO
}

\author{
Angreani A. Djohar ${ }^{1}$, Herman Karamoy $^{2}$, Jessy D. L. Warongan ${ }^{3}$ \\ ${ }^{1,2,3}$ Fakultas Ekonomi dan Bisnis. Jurusan Akuntansi. Universitas Sam Ratulangi, Jl. Kampus Bahu, Manado, \\ 95115, Indonesia. \\ E-mail : angreanidjohar1@gmail.com
}

\begin{abstract}
Income tax article $4(2)$ is the final income tax that is the collection institutions is central government. The auction is a kind of income subject to income tax article 4 (2). The auction tax rate of 2,5\% on PP RI No. 34 year 2016. Service office a wealth of state and of government agencies is Manado auction that runs the basic tasks in the field of auctions. The methods used in this research is descriptive research method is qualitative. As for the purpose of this research is to analyze system cutting the income tax article 4 (2) on auction at the service office a wealth of state and the auction Manado. Based on research results from service office a wealth of state and the auction Manado cutting of the income tax article 4 (2) is in compliance to applicable government regulations. Service office a wealth of state and the auction Manado are expected to carry out the duty taxes according government regulation and improve understanding and active in the running of government regulation.
\end{abstract}

Keywords : Income Tax Article 4 (2), Cutting, Auction

\section{PENDAHULUAN}

Indonesia merupakan salah satu negara berkembang yang saat ini sedang melaksanakan pembangunan disegala bidang. Pembangunan tersebut sangatlah penting sehingga menjadi perhatian yang cukup serius baik dari pihak pemerintah maupun dari pihak masyarakat, karena dengan adanya pembangunan tersebut diharapkan dapat menciptakan kehidupan masyarakat yang lebih baik, lebih maju, dan lebih sejahtera. Untuk mewujudkan kemandirian dalam pembangunan tersebut diperlukan biaya yang relatif tidak sedikit. Salah satu upaya yang dilakukan pemerintah untuk membiayai pembangunan tersebut ialah dengan menggali dan menggerakkan segala potensi dibidang pajak.

Menurut Adriani, pajak adalah iuran masyarakat kepada negara (yang dapat dipaksakan) yang terutang oleh yang wajib membayarnya menurut peraturan-peraturan umum (undang-undang) dengan tidak mendapat prestasi kembali yang langsung dapat ditunjuk dan yang gunanya adalah untuk membiayai pengeluaran-pengeluaran umum berhubung tugas negara untuk menyelenggarakan pemerintahan. Pajak merupakan peranan yang sangat penting dalam memenuhi kepentingan masyarakat. Tanpa adanya pajak, maka pembangunan pemerintah tidak akan berjalan dengan lancar. Hal tersebut dapat dipahami karena dengan adanya pajak disebabkan oleh adanya kepentingan masyarakat dalam memenuhi kebutuhan masyarakat, sehingga masyarakat diwajibkan untuk membayar pajak.

Pajak merupakan penerimaan terbesar negara, sekitar $70 \%$ penerimaan negara berasal dari pajak itu. Itu berarti pajak memberikan kontribusi yang terbesar bagi penerimaan negara sehingga manfaat dari pajak telah dapat dirasakan oleh seluruh lapisan masyarakat dalam berbagai bidang, meliputi kesehatan, pendidikan, infrastuktur dan sebagainya.

Penerimaan pajak penghasilan $(\mathrm{PPh})$ merupakan salah satu penerimaan terbesar dari penerimaan Negara. Penerimaan PPh ini diharapkan dapat terus meningkat seiring dengan pertumbuhan dunia usaha nasional. Untuk itu pemerintah mulai melaksanakan suatu terobosan yaitu dengan menerapkan sistem pengenaan $\mathrm{PPh}$ yang bersifat final (PPh-Final). 
Berdasarkan Pasal 4 ayat (2) undang-undang pajak penghasilan, memberikan mandat kepada pemerintah untuk mengenakan $\mathrm{PPh}$ final atas penghasilan-penghasilan tertentu. Berdasarkan ketentuan ini pemerintah mengeluarkan peraturan pemerintah untuk mengenakan $\mathrm{PPh}$ final atas penghasilan tertentu dengan pertimbangan kesederhanaan, kemudahan, serta pengawasan. Pengenaan PPh Final sebagian berasal dari ketentuan Pasal 4 ayat (2) ini.

Peraturan Menteri Keuangan RI Nomor 27/PMK.06/2016 Pasal 1 angka 1 lelang adalah penjualan barang yang terbuka untuk umum dengan penawaran harga yang tertulis dan/ atau lisan yang semakin meningkat atau menurun untuk mencapai harga tertinggi, yang didahului dengan pengumuman lelang. Sesuai dengan Peraturan Menteri Keuangan Nomor 27/PMK.06/2016 tentang jenis-jenis lelang dibagi menjadi 2 (dua) :

a. Lelang Eksekusi adalah lelang untuk melaksanakan putusan atau penetapan pengadilan, dokumen-dokumen lain yang dipersamakan dengan itu, dan/ atau melaksanakan ketentuan dalam peraturan perundang-undangan.

b. Lelang Non-eksekusi

1) Lelang Non-eksekusi Wajib adalah Lelang untuk melaksanakan penjualan barang yang oleh peraturan perundang-undangan diharuskan dijual secara lelang.

2) Lelang Non-eksekusi Sukarela lelang atas Barang milik swasta, perorangan atau badan hukum/badan usaha yang dilelang secara sukarela.

Kantor Pelayanan Kekayaan Negara dan Lelang (KPKNL) Manado merupakan salah satu unit kerja Direktorat Jenderal Kekayaan Negara Kementrian Keuangan Republik Indonesia yang mempunyai wewenang untuk melakukan pengelolaan kekayaan negara, piutang negara, penilaian dan lelang. Lelang menjadi salah satu tugas pokok yang harus dijalankan oleh Kantor Pelayanan Kekayaan Negara dan Lelang (KPKNL) Manado. Sebagai instansi pemerintah yang melaksanakan lelang tentunya Kantor Pelayanan Kekayaan Negara dan Lelang (KPKNL) Manado juga harus melakukan pengenaan pajak atas lelang yang terjadi baik pemotongan, penyetoran, maupun pelaporan. Kantor Pelayanan Kekayaan Negara dan Lelang (KPKNL) Manado yang menganut sistem pemungutan pajak official assessment system dimana yang berhak melakukan pengenaan pajak adalah bendahara penerimaan Kantor Pelayanan Kekayaan Negara dan Lelang (KPKNL) Manado berdasarkan undangundang yang berlaku, sebagai wujud dari ketaatan atau kepatuhan perpajakan dalam melaksanakan pemungutan pajak. Tujuan penelitian ini untuk menganalisis sistem pemotongan PPh Pasal 4 ayat 2 atas lelang pada Kantor Pelayanan Kekayaan Negara dan Lelang Manado.

\section{TINJAUAN PUSTAKA}

\subsection{Konsep Perpajakan}

Menurut Prof. Dr. P. J.A. Adriani, pajak adalah iuran masyarakat kepada negara (yang dapat dipaksakan) yang terutang oleh wajib pajak yang wajib membayarnya menurut peraturan-peraturan umum (undang-undang) dengan tidak mendapat prestasi kembai yang langsung dapat ditunjuk dan yang gunanya adalah untuk membiayai pengeluaran-pengeluaran umum berhubung tugas negara untuk menyelenggarakan pemerintahan (Waluyo 2013:2).

\subsection{Fungsi Perpajakan}

Menurut Prof. Dr. P. J.A. Adriani, pajak adalah iuran masyarakat kepada negara (yang dapat dipaksakan) yang terutang oleh wajib pajak yang wajib membayarnya menurut peraturan-peraturan umum (undang-undang) dengan tidak mendapat prestasi kembai yang langsung dapat ditunjuk dan yang gunanya adalah untuk membiayai pengeluaran-pengeluaran umum berhubung tugas negara untuk menyelenggarakan pemerintahan (Waluyo 2013:2). 


\subsection{Sistem Pemungutan Pajak}

1.Official Assessment System

Adalah suatu sistem pemungutan yang memberi wewenang kepada pemerintah (fiskus) untuk menentukan besarnya pajak yang terutang oleh wajib pajak.

2.Self Assessment System

Adalah suatu sistem pemungutan pajak yang memberi wewenang kepada wajib pajak untuk menentukan sendiri besarnya pajak yang terutang.

3. Withholding System

Adalah suatu pemungutan pajak yang memberi wewenang kepada pihak ketiga (bukan fiskus dan bukan wajib pajak yang bersangkutan) untuk memotong atau memungut pajak yang terutang oleh wajib pajak.

\subsection{Pajak Penghasilan}

Mardiasmo (2011:155) Undang-Undang No.7 Tahun 1984 tentang Pajak Penghasilan $(\mathrm{PPh})$ berlaku sejak 1 Januari 1984. Undang-Undang Pajak Penghasilan (PPh) mengatur pengenaan pajak penghasilan terhadap subjek pajak berkenaan dengan penghasilan yang diterima atau diperolehnya dalam tahun pajak. Subjek pajak tersebut dikenai pajak apabila menerima atau memperoleh penghasilan.

\subsection{Pajak Penghasilan Pasal 4 Ayat 2}

Mardiasmo (2016:319) Pasal 4 ayat (2) Undang-Undang Pajak Penghasilan menyebutkan, bahwa : Atas penghasilan berupa bunga deposito, dan tabungan-tabungan lainnya, penghasilan dari transaksi saham dan sekuritas lainnya di bursa efek, penghasilan dari pengalihan harta berupa tanah dan/atau bangunan serta penghasilan tertentu lainnya, pengenaan pajaknya diatur dengan Peraturan Pemerintah. Sedangkan menurut Lubis (2015:20) PPh Pasal 4 ayat 2 (Final) adalah transaksi pembayaan bunga bank, sewa tanah dan bangunan, hadiah undian, bunga simpanan koperasi, jasa konstruksi, dan dividen dibayar kepada wajib pajak orang pribadi.

\subsection{Tata Cara Pemotongan PPh Pasal 4 ayat 2}

Tata cara pemotongan Pajak Penghasilan Final atas pengalihan hak atas tanah dan/atau bangunan berdasarkan Peraturan Pemerintah Republik Indonesia Nomor 34 Tahun 2016:

1. Dikenakan tarif $2,5 \%$ dari jumlah bruto pengalihan;

Tarif yang dikenakan adalah 2,5\% dari jumlah bruto nilai pengalihan (nilai tertinggi antara nilai berdasarkan akta jual beli/pengalihan dan NJOP tanah dan bangunan sesuai SPPT PBB).

2. Nilai menurut risalah lelang;

menurut risalah lelang, dalam hal pengalihan hak sesuai dengan peraturan lelang (Vendu Reglement Staatsblad Tahun 1908 Nomor 189 beserta perubahannya). Nilai risalah lelang dalah pokok lelang yang diperoleh dari transaksi lelang yang terjadi.

3. Dipungut pajak penghasilan oleh bendahara pemerintah atau pejabat yang melakukan pembayaran atau pejabat yang menyetujui tukar menukar.

\subsection{Tata Cara Penyetoran PPh Pasal 4 Ayat 2}

Tata cara penyetoran PPh Pasal 4 Ayat 2 atas pengalihan hak atas tanah dan/atau bangunan :

1. Orang pribadi atau badan yang menerima atau memperoleh penghasilan dari pengalihan hak atas tanah dan/atau bangunan wajib menyetor sendiri pajak penghasilan yang terutang, sebelum risalah lelang ditanda tangani oleh pejabat lelang;

2. Bendahara pemerintah atau pejabat wajib pajak menyetor pajak penghasilan yang telah dipungut (dipotong) ke bank/pos persepsi; 
3. Penyetoran dilakukan atas nama orang pribadi atau badan yang menerima pembayaran atau melakukan tukar menukar, bukan atas nama bendahara pemerintah atau pejabat pemungut;

4. Penyetoran dilakukan dengan menggunakan surat setoran pajak atau sarana administrasi lainnya.

\subsection{Tata Cara Pelaporan PPh Pasal 4 Ayat 2}

Tata cara pelaporan berdasarkan Peraturan Pemerintah Republik Indonesia Nomor 34 Tahun 2016 :

1. Pejabat lelang yang menandatangani risalah lelang wajib menyampaikan laporan bulanan mengenai penerbitan risalah lelang atas pengalihan hak atas tanah dan/atau bangunan kepada Direktorat Jenderal Pajak;

2. Wajib melakukan pelaporan perpajakan mengenai pengalihan hak atas tanah dan/atau bangunan.

\subsection{Penelitian Terdahulu}

1. Tangka (2014) dengan judul : Analisis Perhitungan PPh Final Pasal 4 Ayat (2) Atas Bunga Deposito Dan Tabungan Nasabah Pada PT. Bank Rakyat Indonesia (Persero), tbk Cabang Manado. Tujuan penelitian untuk mengetahui bagaimana perhitungan bunga serta pemotongan pajak penghasilan final atas bunga tabungan dan deposito nasabah pada PT. Bank Rakyat Indonesia (persero), Tbk cabang Manado. Metode yang digunakan deskriptif. Hasil penelitian menunjukan perhitungan pajak penghasilan final pasal 4 ayat 2 atas bunga deposito dan tabungan PT. Bank Rakyat Indonesia (Persero), tbk cabang Manado telah sesuai dengan perundang-undangan yang berlaku.

2. Utama (2011) dengan judul : Analisis Pengaruh Pemungutan PPh Final Atas Pengalihan Hak Atas Tanah Dan/Atau Bangunan Pada Aspek Keuangan Perusahaan Real Estate PT. Baruga Asrinusa Development. Tujuan penelitian untuk mengetahui penerapan PPh Final pada PT Baruga Asrinusa sudah sesuai dengan PP nomor 71 tahun 2008 dan pengaruh PPh Final terhadap laba rugi PT. Baruga Asrinusa. Metode yang digunakan deskriptif. Hasil penelitian PT. Baruga Asrinusa Development telah menerapkan peraturan dari pajak dengan menggunakan tarif PPh Final dalam setiap pengalihan hak atas tanah dan/atau bangunan sebesar 5\% sehingga PT. Baruga Asrinusa Development selalu melunasi pembayaran PPh Finalnya setiap terjadinya transaksi.

3. Muhea (2016) dengan judul : Analisis Penyetoran, Pelaporan, Dan Pencatatan PPh Final Pasal 4 Ayat (2) Atas Bunga Deposito Dan Tabungan Nasabah Pada Bpr Prisma Dana Cabang Amurang. Tujuan penelitian untuk mengetahui kesesuaian antara penyetoran, pelaporan, dan pencatatan PPh Final pasal 4 ayat (2) atas bunga deposito dan tabungan nasabah pada PT. BPR Prisma Dana cabang Amurang dengan Ketentuan Perpajakan yang berlaku. Metode penelitian deskriptif. Hasil penelitian BPR Prisma Dana cabang Amurang sudah melakukan pemotongan, penyetoran, dan melaporkan Pajak Penghasilan Final pasal 4ayat (2)atas bunga deposito dan tabungan.

\section{METODE PENELITIAN}

\subsection{Jenis Penelitian}

Jenis penelitian yang digunakan adalah penelitian deskriptif. Dantes (2012:51) penelitian deskriprif diartikan sebagai suatu penelitian yang berusaha mendeskripsikan suatu fenomena/peristiwa secara sistematis dengan apa adanya. Sedangkan Suryabrata (2013: 75) penelitian deskriptif merupakan jenis penelitian yang tujuannya untuk membuat gambaran secara sistematis, faktual, dan akurat mengenai fakta-fakta dan sifat-sifat populasi atau daerah tertentu. 


\subsection{Tempat dan Waktu Penelitian}

Penelitian ini dilakukan di Kantor Pelayanan Kekayaan Negara dan Lelang Manado. Proses penelitian ini dilakukan dalam waktu 3 bulan yaitu pada bulan Mei sampai bulan Juli 2017.

\subsection{Prosedur Penelitian}

Prosedur yang dilakukan dalam skripsi ini adalah :

1. Melalukan Survey Awal

2. Melakukan Wawancara

3. Mengumpulkan Data

4. Menganalisis Data

5. Menarik Kesimpulan

\subsection{Metode Pengumpulan Data}

\section{Jenis Data}

Jenis data yang digunakan peneliti dalam penelitian ini adalah data kualitatif yang disajikan dalam bentuk kata-kata.

\section{Sumber Data}

a. Sumber primer

Melakukan wawancara secara langsung dengan bendahara penerimaan KPKNL serta pihak-pihak yang terkait antara lain pejabat lelang dan asisten lelang.

b. Sumber sekunder

Data yang diperoleh dari tanggan kedua berupa artikel ilmiah, arsip, laporan, buku, majalah, catatan publik atau gambar-gambar.

\section{Teknik pengumpulan data}

Dalam teknik pengumpulan data ini menggunakan teknik wawancara dan observasi karena penulis melakukan wawancara langsung dengan bendahara penerimaan KPKNL dan pihak-pihak yang terkait.

\subsection{Metode Analisis}

Metode yang digunakan dalam penulisan skripsi ini adalah metode deskriptif yang bersifat kualitatif yaitu metode yang dilakukan peneliti dengan cara mengetahui sistem dan prosedur dasar pengenaan pokok lelang, cara perhitungan, penyetoran dan pelaporan dalam 2 tahun, kemudian ditarik kesimpuln mengenai analisis pemotongan PPh Pasal 4 ayat 2 terhadap lelang pada Kantor Pelayanan Kekayaan Negara dan Lelang Manado apakah sistem yang digunakan sudah sesuai dengan peraturan pemerintah yang ada.

\section{HASIL ANALISIS DAN PEMBAHASAN}

\subsection{Hasil analisis}

4.1.1. Pemotongan PPh Pasal 4 Ayat 2 Terhadap Lelang Pada Kantor Pelayanan Kekayaan Negara dan Lelang Manado

Kantor Pelayanan Kekayaan Negara dan Lelang (KPKNL) Manado yang menganut sistem pemungutan pajak official assessment system yang memberikan wewenang kepada bendahara penerimaan Kantor Pelayanan Kekayaan Negara dan Lelang (KPKNL) Manado untuk melakukan pemotongan atas transaksi lelang yang terjadi. Sebelum bendahara penerimaan Kantor Pelayanan Kekayaan Negara dan Lelang (KPKNL) Manado melakukan pemotongan atas transaksi lelang yang terjadi, terlebih dahulu pejabat lelang melakukan perhitungan atas pajak yang akan dikenakan berdasarkan Peraturan Pemerintah Republik Indonsesia Nomor 34 Tahun 2016 dengan tarif :

a. 2,5\% (dua koma lima persen) dari jumlah bruto nilai pengalihan hak atas tanah dan/ atau bangunan selain pengalihan hak atas tanah dan/ atau bangunan berupa rumah sederhana atau rumah susun sederhana yang dilakukan oleh wajib pajak yang usaha pokoknya melakukan pengalihan hak atas tanah dan/ atau bangunan; 
b. 1\% (satu persen) dari jumlah bruto nilai pengalihan hak atas tanah dan/atau bangunan berupa Rumah Sederhana dan Rumah Susun Sederhana yang dilakukan oleh Wajib Pajak yang usaha pokoknya melakukan pengalihan hak atas tanah dan/ atau bangunan; atau

c. $0 \%$ (nol persen) atas pengalihan hak atas tanah dan/atau bangunan kepada pemerintah, badan usaha milik negara yang mendapat penugasan khusus dari Pemerintah, atau badan usaha milik daerah yang mendapat penugasan khusus dari kepala daerah, sebagaimana dimaksud dalam undang-undang yang mengatur mengenai pengadaan tanah bag, pembangunan untuk kepentingan umum.

Pengenaan tarif pajak untuk lelang sebesar 2,5\% dari jumlah bruto nilai pengalihan, pengenaan tarif pajak sebesar 2,5\% dikarenakan penghasilan yang dikenakan pajak merupakan hasil dari transaksi lelang yang dilakukan oleh KPKNL Manado selaku instansi pemerintah yang tugas pokoknya adalah melaksanakan lelang tanah dan bangunan yang tentunya harus melakukan pengenaan pajak atas lelang yang terjadi dan jumlah bruto merupakan nilai menurut risalah lelang yang sudah ditetapkan oleh pejabat lelang.

d.

Tabel 4.1 Pemotongan Pajak Penghasilan Pasal 4 Ayat 2 Atas Lelang Pada KPKNL Manado Tahun 2015

\begin{tabular}{llcccc}
\hline No. & Objek Lelang & $\begin{array}{c}\text { Pokok Lelang } \\
(\mathrm{Rp})\end{array}$ & $\begin{array}{c}\text { Tarif } \\
\text { Pajak }\end{array}$ & $\begin{array}{c}\text { PPh } \\
(\mathrm{Rp})\end{array}$ & $\begin{array}{c}\text { Hasil Bersih } \\
\text { Lelang }\end{array}$ \\
\hline 1. & $\begin{array}{l}\text { Sebidang tanah } \\
\text { dan bangunan }\end{array}$ & Rp. 10.100 .000 & $5 \%$ & Rp. 505.000 & Rp. 9.595 .000 \\
2. & $\begin{array}{l}\text { Sebidang tanah } \\
\text { dan bangunan }\end{array}$ & Rp.15.350.000 & $5 \%$ & Rp. 767.500 & Rp. 14.582500 \\
3. & $\begin{array}{l}\text { Sebidang tanah } \\
\text { dan bangunan }\end{array}$ & Rp. 15.350 .000 & $5 \%$ & Rp. 767.500 & Rp. 14.582500 \\
4. & $\begin{array}{l}\text { Sebidang tanah } \\
\text { dan bangunan }\end{array}$ & Rp. 30.100 .000 & $5 \%$ & Rp. 1.505 .000 & Rp. 28.595 .000 \\
\hline
\end{tabular}

Sumber : Kantor Pelayanan Kekayaan Negara dan Lelang Manado, data diolah 2017

Tabel 4.2 Pemotongan Pajak Penghasilan Pasal 4 Ayat 2 Atas Lelang Pada KPKNL Manado Tahun 2016

\begin{tabular}{|c|c|c|c|c|c|c|}
\hline No. & Objek Lelang & $\begin{array}{c}\text { Pokok Lelang } \\
\text { (Rp) }\end{array}$ & $\begin{array}{l}\text { Tarif } \\
\text { Pajak }\end{array}$ & & $\begin{array}{l}\mathrm{PPh} \\
\mathrm{Rp})\end{array}$ & $\begin{array}{l}\text { Hasil Bersih } \\
\text { Lelang }\end{array}$ \\
\hline 1. & $\begin{array}{l}\text { Sebidang tanah } \\
\text { dan bangunan }\end{array}$ & Rp. 25.605 .000 & $2,5 \%$ & Rp. & 640.125 & Rp. 24.964 .875 \\
\hline 2. & $\begin{array}{l}\text { Sebidang tanah } \\
\text { dan bangunan }\end{array}$ & Rp. 551.000 .000 & $2,5 \%$ & Rp. & 13.775 .000 & Rp. 537.225.000 \\
\hline 3. & $\begin{array}{l}\text { Sebidang tanah } \\
\text { dan bangunan }\end{array}$ & Rp. 47.200 .000 & $2,5 \%$ & Rp. & 1.180 .000 & Rp. 46.020.000 \\
\hline 4. & $\begin{array}{l}\text { Sebidang tanah } \\
\text { dan bangunan }\end{array}$ & Rp. 200.100 .000 & $2,5 \%$ & Rp. & 5.002 .500 & Rp. 195.097.500 \\
\hline
\end{tabular}

Sumber : Kantor Pelayanan Kekayaan Negara dan Lelang Manado, data diolah 2017

Pokok lelang diperoleh dari kesepakatan harga antara pembeli dan pejabat lelang. Setelah pokok lelang sudah telah disepakatu antara pembeli dan pejabat lelang selanjutnya pembeli wajib melakukan pelunasan harga pokok lelang sesuai dengan waktu yang ditetapkan oleh pejabat lelang biasanya 5 (lima) hari kerja setelah tanggal risalah lelang. 
Pembeli melakukan pelunasan harga pokok lelang ke rekening bendahara penerimaan KPKNL Manado.

\subsection{Pembahasan}

4.3. Analisis Pemotongan PPh Pasal 4 Ayat 2 Terhadap Lelang Pada Kantor Pelayanan Kekayaan Negara dan Lelang Manado

Tata cara pemotongan berdasarkan Peraturan Pemerintah Nomor 34 Tahun 2016 sebagai berikut :

1. Dikenakan tarif $2,5 \%$ dari jumlah bruto pengalihan

2. Nilai menurut risalah lelang

3. Dipungut pajak penghasilan oleh bendahara pemerintah atau pejabat yang melakukan pembayaran atau pejabat yang menyetujui tukar menukar.

\section{KESIMPULAN DAN SARAN}

\subsection{Kesimpulan}

Berdasarkan hasil penelitian yang telah dilakukan dan pembahasan yang telah dilakukan oleh peneliti pada bab sebelumya, peneliti menarik kesimpulan bahwa :

1. Pemotongan PPh Pasal 4 ayat 2 terhadap lelang pada Kantor Pelayanan Kekayaan Negara dan Lelang (KPKNL) Manado telah sesuai dengan Peraturan Pemerintah mengingat bahwa landasan Kantor Pelayanan Kekayaan Negara dan Lelang (KPKNL) Manado untuk melakukan pemotongan pajak adalah Peraturan Pemerintah Republik Indonesia Nomor 36 Tahun 2016.

2. Dalam pemotongan pajak yang dilakukan oleh bendahara penerimaan Kantor Pelayanan Kekayaan Negara dan Lelang (KPKNL) Manado sudah sesuai dengan tarif yang ditetapkan dalam Peraturan Pemerintah yaitu 2,5\% (dua koma lima persen) dari jumlah bruto nilai pengalihan.

\subsection{Saran}

Berdasarkan kesimpulan, maka peneliti memberi saran-saran sebagai berikut :

1. Kantor Pelayanan Kekayaan Negara dan Lelang (KPKNL) Manado sebagai intansi pemerintah yang tugas pokoknya yaitu melaksanakan lelang yang dikenakan Pajak Penghasilan Final Pasal 4 Ayat 2 agar dapat terus melaksanakan kegiatan perpajakan dalam pemotongan pajak seusai dengan aturan dan tata acara yang berlaku, dan dapat terus berperan aktif dalam menjalankan peraturan pemerintah, mengingat pajak merupakan sumber penerimaan terbesar pemerintah khususnya pemerintah pusat.

2. Kantor Pelayanan kekayaan Negara dan Lelang (KPKNL) Manado juga harus mengetahui tentang undang-undang maupun peraturan pemerintah yang terbaru, agar tidak terjadi kesalahan dalam pelaksanaan perpajakan khususnya dalam pemotongan pajak.

\section{DAFTAR PUSTAKA}

Dantes, N, 2012, MetodePenelitian. Andi. Yogyakarta.

Diana. A \&Setiawati. L, 2014. PerpajakanTeoridanPeraturanTerkini. Edisi ke-1. Andi. Yokyakarta.

Ilyas, W \& Burton, 2011. HukumPajak. Edisi ke-5. SalembaEmpat. Jakarta.

Lubis, I, 2015, MahirAkuntansiPajakTerapan. Edisi ke-1. Andi. Yogyakarta.

Mardiasmo, 2011. Perpajakan. EdisiRevisi. Penertbit Andi. Yogyakarta.

Mardiasmo, 2016. Perpajakan. EdisiRevisi.Penerbit Andi. Yogyakarta.

Muhea., T. Marchella, 2016, Analisis Penyetoran, Pelaporan, Dan Pencatatan PPh Final Pasal 4 Ayat (2) Atas Bunga Deposito Dan Tabungan Nasabah Pada Bpr Prisma Dana 
Cabang Amurang. Jurnal Emba. ISSN2303-1174. Vol 11, Hal 120-129.Fakultas Ekonomi dan Bisnis. Universitas Sam Ratulangi. Manado.

Riandini., Vera A, 2015, Lelang Eksekusi Hak Tanggungan Dengan Kreditur Bank Pemerintah Di Kantor Pelayanan Kekayaan Negara Dan Lelang (KPKNL) Semarang. Skripsi. Universitas Negeri Semarang. Semarang.

Republik Indonesia, Peraturan Menteri KeuanganNomor 27/PMK.06/2016, tentang Petunjuk Pelaksanaan Lelang.

Republik Indonesia, Peraturan Menteri Keuangan Nomor 34 Tahun 2016, tentang Pajak Penghasilan Atas Pengalihan Dari Pengalihan Hak Atas Tanah dan/atau Bangunan, dan Perjanjian Pengikatan Jual Beli Atas Tanah dan/atau Bangunan Beserta Perubahannya.

Suryabrata. S, 2013. MetodePenelitian. PT. Raja GrafindoPersada. Jakarta.

Tangka., Ireine S, 2014, Analisis Perhitungan PPh Final Pasal 4 Ayat (2) Atas Bunga Deposito Dan Tabungan Nasabah Pada PT. Bank Rakyat Indonesia (Persero), tbk Cabang Manado. Jurnal Emba. ISSN 2303-1174.Vol 2. Hal 203-212.Fakultas Ekonomi dan Bisnis, Universitas Sam Ratulangi. Manado.

Utama., P. R. Muhammad, 2011, Analisis Pengaruh Pemungutan PPh Final Atas Pengalihan HakAtas Tanah dan/atau Bangunan Pada Aspek Keuangan Perusahaan Real Estate PT. Baruga Asrinusa Development.Skripsi. UniversitasHasanuddin. Makasar.

Waluyo. 2013. Perpajakan Indonesia. Edisi ke-11. SalembaEmpat. Jakarta.

Waluyo, 2014. AkuntansiPajak. Edisi ke-5. SalembaEmpat. Jakarta. 